\title{
The Impact of Catheter Removal Time on Urinary Continence and Overactive Bladder Symptoms After Robot-Assisted Radical Prostatectomy: A Retrospective Analysis of Consecutive 250 Cases From a Single Institution
}

\section{Han Hao}

Department of Urology, Peking University First Hospital

\section{Xu Chen}

Department of Urology, Peking University First Hospital

\section{Yue Liu}

Department of Urology, Peking University First Hospital

\section{Longmei Si}

Department of Urology, Peking University First Hospital

\section{Yuke Chen}

Department of Urology, Peking University First Hospital

\section{Meng Zhang}

Department of Urology, Peking University First Hospital

Wei Yu

Department of Urology, Peking University First Hospital

\section{Yi Song}

Department of Urology, Peking University First Hospital

\section{Shiliang Wu}

Department of Urology, Peking University First Hospital

\section{Zhongyuan Zhang}

Department of Urology, Peking University First Hospital

\section{Zheng Zhao}

Department of Urology, Peking University First Hospital Cheng Shen ( $\square$ shencheng@263.net)

Department of Urology, Peking University First Hospital

\section{Wenke Han}

Department of Urology, Peking University First Hospital 
Keywords: robot-assisted radical prostatectomy, catheter removal time, urinary continence, overactive bladder symptoms

Posted Date: November 10th, 2021

DOI: https://doi.org/10.21203/rs.3.rs-1032948/v1

License: (1) This work is licensed under a Creative Commons Attribution 4.0 International License. Read Full License 


\section{Abstract}

Background After radical prostatectomy, the optimal length of postoperative catheterization time remains to be determined. This study investigates the impact of catheter removal time on urinary continence and overactive bladder symptoms after robot-assisted radical prostatectomy (RARP).

Methods Two hundred and fifty consecutive patients underwent RARP by a single surgeon between November 2020 and May 2021. Time to catheter removal was categorized into 7, 10, and $\geq 14$ days. Continence was defined as no more than 1 pad used or no more than 20 grams of urine leakage per 24 hours. The patients' continence rates and overactive bladder symptom score (OABSS) were assessed at 48 hours, 1 week, 4 weeks, 12 weeks, and 24 weeks after catheter removal.

Results Overall, continence rates were $36 \% 48$ hours after catheter removal, 55.6\% 1 week, $74.8 \% 4$ weeks, $98.4 \% 12$ weeks, and $100 \% 24$ weeks after catheter removal. The median time to regain continence was 1 week. After stratification according to catheterization time, no significant difference in continence rates was found between different groups at each time point after catheter removal. Longer catheterization was not an independent predictor of continence recovery (10 days: OR 0.985, 95\% $\mathrm{Cl} 0.689-1.409, p=$ $0.936 ; \geq 14$ days: OR $1.194,95 \% \mathrm{Cl} 0.869-1.642, p=0.274)$. The presence of diabetes was associated with worse continence outcomes (OR 1.535, 95\% Cl 1.105-2.132, $p=0.011)$. The mean OABSS of patients in the continent group were significantly lower than the incontinent group at 48 hours, 1 week, and 4 weeks after catheter removal. No significant difference in OABSS was found between different catheterization time groups at each time point after catheter removal.

Conclusions Our results demonstrated that different catheterization time ( 7 days, 10 days, $\geq 14$ days) is not associated with short-, intermediate-, long-term continence outcomes or overactive bladder symptoms.

\section{Introduction}

For patients with localized prostate cancer, robot-assisted radical prostatectomy (RARP) is a reliable treatment option. After radical prostatectomy, the catheter was indwelling for 7 to 14 days to ensure the vesicourethral anastomosis healing, while several studies have reported that removing the catheter within 7 days was also safe and feasible [1]. There are conflicting data as to whether the length of catheterization time has an impact on urinary continence recovery [2-5]. Prolonged catheterization increases the risk of urinary tract infection and may cause patient discomfort [6-8], and it has been reported that prolonged catheterization can adversely affect short- and intermediate-term continence recovery [2]. However, Patel et al. have reported that early removal of the urinary catheter 3 or 4 days after surgery was associated with a significant increase in the incidence of acute urinary retention[9]. Therefore, the optimal length of postoperative catheterization remains to be determined.

Post-prostatectomy overactive bladder (OAB) symptoms are common, which may adversely affect continence recovery [10]. However, whether early removal of the urinary catheter will result in more 
pronounced bladder irritation symptoms due to functional changes of the bladder is still unknown.

The present retrospective study was designed to determine whether different catheterization time has an impact on continence recovery. Overactive bladder symptom score (OABSS) was assessed to evaluate the degree of bladder irritation after catheter removal.

\section{Patients And Methods}

\section{Patient population}

From November 2020 to May 2021, 261 patients with localized prostate cancer underwent RARP by the same experienced surgeon at the Department of Urology, Peking University First Hospital. The study was approved by the institutional review board. Patients who met the enrollment criteria were included. The inclusion criteria were localized prostate cancer (cT1-3, cN0, cM0). Exclusion criteria were as follows: other type of urinary diversion was performed $(N=1)$; incontinence prior to RARP $(N=1)$; patients who were lost to follow-up or died within six months after surgery $(N=9)$.

\section{Surgical methods}

All RARP cases were performed using the transabdominal approach. Total periurethral reconstruction was routinely performed in all cases to improve early continence. The vesicourethral anastomosis was performed by using a 3-0 self-locking running suture. For low-risk patients, a neurovascular bundle (NVB) sparing procedure is performed. Bilateral pelvic lymph node dissection was routinely performed in highrisk patients. The pelvic drains were removed when the drainage was less than $200 \mathrm{~mL}$ during a 24-hour period.

\section{Catheter removal time}

After surgery, all patients were instructed to undergo proper pelvic floor rehabilitation. All patients make an appointment to have their urinary catheter removed before discharge. Catheterization time was based on the individual patient's decision. Patients can choose to have their catheters removed at 7, 10 or 14 days after surgery at their own willingness. Cystography was routinely performed to confirm that there was no anastomotic leak. If the cystogram shows evidence of extravasation, the catheter is retained for at least 14 days.

\section{Follow-up}

Self-administered questionnaires were used at different times (48 hours, 1 week, 4 weeks, 12 weeks, and 24 weeks) after catheter removal, including the number of pads used per 24 hours and OABSS. The patients were also instructed to perform the 24-h pad weight test to accurately record the severity of 
incontinence. Continence was defined as no more than 1 pad used or no more than 20 grams of urine leakage per 24 hours.

\section{Statistical analysis}

All continuous variables are presented as the median and interquartile range (IQR), and the frequencies and proportions were reported as percentages. The Student's t-test and Mann-Whitney U test were used to assess quantitative parametric and nonparametric variables, respectively. The chi-square test was used to assess differences in distributions between categorical parameters. All reported $p$ values were obtained using the two-sided exact method at the conventional $5 \%$ significance level. The patients' continence rates were assessed at 48 hours, 1 week, 4 weeks, 12 weeks, and 24 weeks after catheter removal. Kaplan-Meier curves were used to determine the incontinence probability among the patients. Variables associated with continence recovery were analyzed using the Cox proportional hazards model, adjusting for age, body mass index (BMI), prostate volume, pre-operative International Prostate Symptom Score (IPSS), pre-operative OABSS, prostate specific antigen (PSA), diabetes mellitus, NVB preservation, margin status. All analyses were performed using IBM® SPSS ${ }^{\circledR}$ Statistics Version 23.0 (International Business Machines Corporation, New York, USA).

\section{Results}

\section{Clinical and pathological data}

A total of 250 patients were enrolled in this study. Clinical information of the patient population is detailed in Table 1, stratified by catheterization time. The median age was 66.0 years (IQR 62.0-70.3) and the median PSA level was $9.06 \mathrm{ng} / \mathrm{ml}$ (IQR 5.70-14.97). Patients with longer catheterization ( $\geq 14$ days) were significantly older. 
Table 1

Clinical characteristics

\begin{tabular}{|c|c|c|c|c|c|}
\hline \multirow{3}{*}{$\begin{array}{l}\text { Patients' } \\
\text { characteristics }\end{array}$} & \multirow{3}{*}{$\begin{array}{l}\text { Overall Data } \\
(n=250)\end{array}$} & \multicolumn{3}{|c|}{ Catheterization time (days) } & \multirow{3}{*}{$\begin{array}{l}p \\
\text { value }\end{array}$} \\
\hline & & 7 & 10 & $\geq 14$ & \\
\hline & & $(n=37)$ & $(n=50)$ & $(n=163)$ & \\
\hline Age, yr & $\begin{array}{l}66.0 \otimes 62.0- \\
70.3 \rrbracket\end{array}$ & $65(58-68.5)$ & $\begin{array}{l}65.5(62.75- \\
71)\end{array}$ & $67(62-71)$ & $0.038 *$ \\
\hline $\mathrm{BMI}$ & $\begin{array}{l}24.8 \rrbracket 23.0- \\
26.7 \rrbracket\end{array}$ & $\begin{array}{l}24.2(22.2- \\
27.6)\end{array}$ & $\begin{array}{l}25.3(23.4- \\
26.7)\end{array}$ & $\begin{array}{l}24.8(23.0- \\
26.4)\end{array}$ & 0.877 \\
\hline PSA, ng/ml & $\begin{array}{l}9.06 \rrbracket 5.70- \\
14.97 \rrbracket\end{array}$ & $\begin{array}{l}10.77(6.47- \\
14.69)\end{array}$ & $\begin{array}{l}8.28(4.10- \\
12.84)\end{array}$ & $\begin{array}{l}9.11(5.35- \\
15.61)\end{array}$ & 0.752 \\
\hline Pre-operative IPSS & $8 \rrbracket 3-15 \rrbracket$ & $8(2-17)$ & $8(3-12)$ & $8(4-16)$ & 0.632 \\
\hline $\begin{array}{l}\text { Pre-operative } \\
\text { OABSS }\end{array}$ & $3 \rrbracket 2-5 \rrbracket$ & $3(1-5.5)$ & $3(2-4)$ & $3(2-5)$ & 0.368 \\
\hline Prostate volume, ml & $\begin{array}{l}35.2 \rrbracket 24.5- \\
50.8 \rrbracket\end{array}$ & $\begin{array}{l}35.0(27.5- \\
47.3)\end{array}$ & $\begin{array}{l}34.5(22.1- \\
45.4)\end{array}$ & $\begin{array}{l}35.2(24.6- \\
53.0)\end{array}$ & 0.356 \\
\hline
\end{tabular}

* With statistical significance

Of all patients enrolled, a total of 58 had bilateral lymph node dissection (23.2\%), and 49 had NVB sparing surgery (19.6\%). Postoperative pathology information is detailed in Table 2. Forty-three patients had positive margins (17.2\%). Among all patients who underwent lymph node dissection, lymph node metastasis was found in 9 cases $(3.6 \%)$. 
Table 2

Patients' histopathological data

\begin{tabular}{|c|c|c|c|c|c|}
\hline \multirow[t]{2}{*}{ Pathological findings } & \multirow{2}{*}{$\begin{array}{l}\text { Overall Data } \\
(n=250)\end{array}$} & \multicolumn{3}{|c|}{ Catheterization time (days) } & \multirow[t]{2}{*}{$p$ value } \\
\hline & & $\begin{array}{l}7 \\
(n=37)\end{array}$ & $\begin{array}{l}10 \\
(n=50)\end{array}$ & $\begin{array}{l}\geq 14 \\
(n=163)\end{array}$ & \\
\hline Positive margins, no. (\%) & $43(17.2)$ & $9(24.3)$ & $8(16.0)$ & $26(16.0)$ & 0.461 \\
\hline \multicolumn{6}{|l|}{ Stage, no. (\%) } \\
\hline$\leq \mathrm{pT} 2$ & $120(48.0)$ & $19(51.4)$ & $24(48)$ & $77(47.2)$ & 0.970 \\
\hline$\geq$ pT3 & $128(51.2)$ & $18(48.6)$ & $24(48)$ & $86(52.7)$ & \\
\hline Unable to stage & $2(0.8)$ & & $2(4)$ & & \\
\hline \multicolumn{6}{|l|}{ Gleason score, no.(\%) } \\
\hline $2-6$ & $14(5.6)$ & $2(5.4)$ & $2(4.0)$ & $10(6.1)$ & 0.320 \\
\hline 7 & $152(60.8)$ & $24(55.7)$ & $30(60.0)$ & $98(60.1)$ & \\
\hline $8-10$ & $75(30)$ & $11(29.7)$ & $17(34.0)$ & $53(32.5)$ & \\
\hline Unclassified & $9(3.6)$ & & $1(2.0)$ & $2(1.2)$ & \\
\hline
\end{tabular}

\section{Continence outcomes}

Overall, continence rates were 36\% 48 hours after catheter removal, 55.6\% 1 week, $74.8 \% 4$ weeks, 98.4\% 12 weeks, and 100\% 24 weeks after catheter removal (Fig. 1). The median time to regain continence was 1 week. No cases of acute urinary retention occurred. The number of safety pads used per 24 hours and the 24-h pad weight at different times after catheter removal are detailed in Table 3. After stratification according to catheterization time, no significant difference in continence rates was found between different groups at each time point after catheter removal (Fig. 2). Continence rates at different times are detailed in Table 4.

Table 3

Number of safety pads and 24-h pad weight per day 
Time after catheter removal 24-h pad weight, g/day Number of safety pads, n/day

\begin{tabular}{lll}
\hline $48 \mathrm{hr}$ & $130 \rrbracket 15-500 \rrbracket$ & $2 \rrbracket 1-4 \rrbracket$ \\
\hline $1 \mathrm{wk}$ & $50 \rrbracket 6.4-250 \rrbracket$ & $1 \rrbracket 0-3 \rrbracket$ \\
\hline $4 \mathrm{wk}$ & $15 \rrbracket 2-93 \rrbracket$ & $1 \rrbracket 0-2 \rrbracket$ \\
\hline $12 \mathrm{wk}$ & $3 \rrbracket 1-4 \rrbracket$ & $0 \rrbracket 0-1 \rrbracket$ \\
\hline $24 \mathrm{wk}$ & $2 \llbracket 1-4 \rrbracket$ & $0 \rrbracket 0-1 \rrbracket$
\end{tabular}

Table 4

Continence rates at different times stratified by catheterization time Time after catheter removal Overall Catheterization time (days) p value

\begin{tabular}{llllll} 
& & 7 & 10 & $\geq 14$ & \\
\cline { 3 - 5 } $48 \mathrm{hr}$ & $36.0 \%$ & $27.0 \%$ & $44.0 \%$ & $35.6 \%$ & 0.260 \\
\hline $1 \mathrm{wk}$ & $55.6 \%$ & $51.3 \%$ & $62.0 \%$ & $54.6 \%$ & 0.558 \\
\hline $4 \mathrm{wk}$ & $74.8 \%$ & $72.9 \%$ & $82.0 \%$ & $73.0 \%$ & 0.423 \\
\hline $12 \mathrm{wk}$ & $98.4 \%$ & $100.0 \%$ & $100.0 \%$ & $97.5 \%$ & 0.338 \\
\hline $24 \mathrm{wk}$ & $100.0 \%$ & $100.0 \%$ & $100.0 \%$ & $100.0 \%$ &
\end{tabular}

Kaplan-Meier curves were used to demonstrate incontinence probability stratified by different catheterization times (Fig 3a and b). In a univariate COX regression analysis, the presence of diabetes was associated with worse continence recovery (OR 1.535, 95\% $\mathrm{Cl} 1.105-2.132, p=0.011)$. (Fig 4). It was found that longer catheterization was not an independent predictor of continence recovery (10 days: OR $0.985,95 \% \mathrm{Cl} 0.689-1.409, p=0.936 ; \geq 14$ days: OR 1.194, 95\% Cl 0.869-1.642, $p=0.274)$. However, patients' age, BMI, pre-operative prostate volume, pre-operative PSA, pre-operative IPSS, pre-operative OABSS, NVB preservation, lymph node dissection, and margin status were not associated with continence recovery. The results are detailed in Table 5. 
Table 5

Univariate COX regression, risk factors for continence recovery

\begin{tabular}{|c|c|c|}
\hline Variable & $p$ & $O R(95 \% C l)$ \\
\hline Age & 0.100 & $0.984(0.965-1.003)$ \\
\hline BMI & 0.640 & $0.991(0.954-1.030)$ \\
\hline Diabetes & $0.011 *$ & $1.535(1.105-2.132)$ \\
\hline Prostate Volume & 0.976 & $1.000(0.994-1.006)$ \\
\hline PSA & 0.241 & $1.000(0.999-1.000)$ \\
\hline NVB preservation & 0.953 & $0.991(0.725-1.354)$ \\
\hline Lymph node dissection & 0.852 & $0.972(0.724-1.305)$ \\
\hline Positive margin & 0.942 & $1.988(0.711-1.372)$ \\
\hline Pre-operative IPSS & 0.937 & $1.001(0.984-1.017)$ \\
\hline Pre-operative OABSS & 0.342 & $0.975(0.925-1.027)$ \\
\hline \multicolumn{3}{|l|}{ Catheterization time } \\
\hline 7 days & 0.523 & Ref \\
\hline 10 days & 0.936 & $0.985(0.689-1.409)$ \\
\hline$\geq 14$ days & 0.274 & $1.194(0.869-1.642)$ \\
\hline
\end{tabular}

\section{OAB symptoms and continence recovery}

The results showed that the mean OABSS of patients in the continent group were significantly lower than the incontinent group at 48 hours, 1 week, and 4 weeks after catheter removal (Table 6). No significant difference in OABSS was found between different catheterization time groups at each time point after catheter removal. The results are shown in Table 7. 
Table 6

Mean OABSS at different times after catheter removal according continency

Time after catheter removal

OABSS (mean)

$p$ value

\begin{tabular}{llll} 
& Continent & Incontinent & \\
\hline $48 \mathrm{hr}$ & 6.17 & 8.05 & $<0.001^{*}$ \\
\hline $1 \mathrm{wk}$ & 6.33 & 8.09 & $0.001^{*}$ \\
\hline $4 \mathrm{wk}$ & 4.85 & 7.70 & $<0.001^{*}$ \\
\hline $12 \mathrm{wk}$ & 4.50 & 9.0 & 0.125 \\
\hline $24 \mathrm{wk}$ & 4.18 & & \\
\hline
\end{tabular}

* With statistical significance

Table 7

Mean OABSS at different times after catheter removal stratified by catheterization time

Time after catheter removal

Catheterization time (days)

$p$ value

\begin{tabular}{lllll} 
& 7 & 10 & $\geq 14$ & \\
\cline { 2 - 4 } $48 \mathrm{hr}$ & 7.77 & 7.64 & 7.14 & 0.935 \\
\hline $1 \mathrm{wk}$ & 8.31 & 7.45 & 7.02 & 0.909 \\
\hline $4 \mathrm{wk}$ & 7.31 & 6.55 & 5.68 & 0.367 \\
\hline $12 \mathrm{wk}$ & 5.62 & 4.36 & 4.27 & 0.441 \\
\hline $24 \mathrm{wk}$ & 4.38 & 4.09 & 4.08 & 0.954
\end{tabular}

\section{Discussion}

The "Trifecta" of radical prostatectomy is cancer control, preservation of erectile function, and urinary continence [11]. Although there have been technological advances in recent years, incontinence remains a major complication after radical prostatectomy. The incidence of urinary incontinence ranges from 4 to $31 \%$ at 12 months postoperatively, with an average of $16 \%$ [12]. Postoperative incontinence affects patients' quality of life and reduces their postoperative satisfaction [13]. After radical prostatectomy, the catheter was indwelling for 7 to 14 days to ensure the vesicourethral anastomosis healing. There is no objective evidence regarding the catheter indwelling time after radical prostatectomy, and in most centers, catheterization time was based on individual surgeons' decisions as well as individual patients' factors. The need for more prolonged catheterization is based on the perceived advantage of catheterization in 
preventing urine extravasation, minimizing scar formation, and potentially improving continence. However, there is currently no evidence to support the use of indwelling catheters for prolonged periods. There are conflicting data as to whether the length of catheterization time has an impact on urinary continence recovery. Some studies demonstrated that early catheter removal was associated with a significantly higher continence rate after radical prostatectomy $[4,14]$. Tilki et al. had reported that longer catheterization was associated with worse short- and intermediate-term continence but had no adverse impact on long-term continence [2]. However, Matsushima et al. demonstrated that early catheter removal on postoperative day 2 after laparoscopy radical prostatectomy might increase the risk of incontinence in a randomized controlled trial of 113 cases [5]. At the same time, early removal of the indwelling catheter on postoperative day 3 or 4 might increase the risk of urinary retention and extravasation $[9,15]$. In cases of anastomosis leakage, catheter removal may then be deferred to allow further healing of the anastomosis. Delayed removal of the catheter, on the other hand, has the potential to aggravate urinary tract infections while increasing patient discomfort $[6,8]$. It is also suspected that prolonged catheterization may lead to mechanical damage and inflammation of the urethral and bladder mucosa, which may adversely affect continence outcomes and causing bladder irritation symptoms. Therefore, the optimal length of postoperative catheterization time remains to be determined.

Robotic surgery has greatly reduced the technical difficulty of radical prostatectomy [16]. With the advancement of robotic surgery and the use of total anatomical reconstruction, the quality of vesicourethral anastomosis has gained significant improvement, resulting in better recovery of early urinary continence [17]. In the era of open surgery, urologists prefer to keep the catheter for a more prolonged period. With the advancement of robotic technique, earlier removal of the catheter is tried in order to improve continence recovery and the quality of life.

At the same time, post-prostatectomy $O A B$ symptoms are common. The prevalence of $O A B$ after radical prostatectomy ranges from 15.2 to $37.8 \%$ and may adversely affect continence recovery [10]. Recent studies have highlighted the role of the urethra-genic mechanism in the genesis of post-prostatectomy $O A B$ [18]. There is currently no data on how postoperative management may prevent post-prostatectomy $O A B$. Whether early removal of the urinary catheter will result in less pronounced OAB symptoms is not clear.

Our present study was designed to compare the impact of catheter removal on urinary continence outcomes and OAB symptoms. Favorable continence results were reported for patients undergoing RARP with overall 3-month and 6-month continence rates of 98.4 and $100 \%$. The results showed that removal of the catheter at different times had no significant effect on the patients' early continence (48 hours, 1 week), mid-term continence (4 weeks, 12 weeks), and long-term continence ( 24 weeks). Therefore, early removal of the catheter can be attempted to reduce complications associated with prolonged catheterization, provided that there is no urine extravasation.

The question of whether early removal of the catheter exacerbates bladder irritation symptoms in patients was also explored in this study. We measured OABSS at different times after catheter removal. The 
results showed that the mean OABSS of patients in the continent group was significantly lower than the incontinent group at 48 hours, 1 week, and 4 weeks after catheter removal, which implies that OAB symptoms adversely impact continence recovery. This result suggests that, in addition to anatomical factors, functional changes in the bladder may also be related to the occurrence of postoperative incontinence and merits further exploration. However, in the present study, the results showed that at each time point after catheter removal, the OABSS did not differ significantly between each catheterization group, suggesting that early removal of the catheter does not increase the OAB symptoms of patients. To the best of our knowledge, our retrospective study is the first to identify a relationship between the catheterization time and $\mathrm{OAB}$ symptoms.

In the present study, the presence of diabetes significantly affected continence recovery. Diabetes seems to be a significant disadvantage in gaining urinary continence compared with nondiabetic patients. Our results collaborate with those described in the recent literature $[19,20]$. Diabetes is a systemic disease that can have multiple system involvement, and local recovery of nerve and muscle function after radical prostatectomy may be affected by diabetes. Therefore, diabetic patients should be informed about possible late recovery of postoperative urinary continence compared with nondiabetic patients after RARP.

The present study also has certain limitations. First, this study is a retrospective design with some inherent selection bias. Also, the sample size of this study was relatively small and, the number of cases between each catheterization group was not well matched. The number of patients who had their catheters removed $\geq 14$ days was higher than in the 7-day and 10-day groups. In addition, all RARP procedures were performed by an experienced high-volume surgeon in a single center. Therefore, our results might not be directly transferable to other centers. However, to the best of our knowledge, our study is not only one of the limited studies evaluating the impact of catheterization time on continence outcomes but also one of the few that focused especially on the impact of catheterization on $O A B$ symptoms.

In conclusion, our study demonstrated that different catheterization time ( 7 days, 10 days, $\geq 14$ days) is not associated with short-, intermediate-, long-term continence outcomes or OAB symptoms in a large Chinese RARP cohort.

\section{Abbreviations}

RARP: Robot-assisted radical prostatectomy; IQR: interquartile range; OABSS: overactive bladder symptom score; NVB: neurovascular bundle; IPSS: International Prostate Symptom Score; OAB: overactive bladder; PSA: prostate specific antigen; BMI: Body Mass Index; DM: Diabetes Mellitus; OR: odds ratio; $\mathrm{Cl}$ : confidence interval. 


\section{Declarations}

\section{Acknowledgements}

Not applicable.

\section{Funding}

Nothing to disclose. This research received no specific grant from any funding agency in the public, commercial, or not-for-profit sectors.

\section{Availability of data and materials}

All data generated or analyzed during this study are included in Additional file 1.

\section{Authors' contributions}

$\mathrm{HH}$ collected the patients data, analyzed the data, and drafted and revised the manuscript; XC collected the patients data and analyzed the data; YL collected the patients data; LS was a major contributor in data analysis; YC collected the data; MZ collected the data; $W Y$ collected the data; YS collected the data; SW collected the data; ZZ1 collected the data; ZZ2 collected the data; CS was a major contributor in data analysis and revising the manuscript; WH collected the data. All authors read and approved the final manuscript. (ZZ1 corresponding to Zhongyuan Zhang and ZZ2 corresponding to Zheng Zhao).

\section{Ethics approval and consent to participate}

Present study was approved by the clinical research ethics committee of Peking University First Hospital (Protocol number: 2020[278]), and written informed consent was obtained from all individual participants included in the study. All methods were performed in accordance with the relevant guidelines and regulations.

\section{Consent for publication}

Not application.

\section{Competing interests}

The authors declare that they have no competing interests. 


\section{Author details}

${ }^{1}$ Department of Urology, Peking University First Hospital, 8 Xishiku Street, Xicheng District, Beijing 100034, China. ${ }^{2}$ Institute of Urology, Peking University, National Urological Cancer Center, 8 Xishiku Street, Xicheng District, Beijing 100034, China.

\section{References}

1. Koch MO, Nayee AH, Sloan J, Gardner T, Wahle GR, Bihrle R, Foster RS: Early catheter removal after radical retropubic prostatectomy: long-term followup. J Urol 2003, 169(6):2170-2172.

https://doi.org/10.1097/01.ju.0000065860.16392.19

2. Tilki D, Preisser F, Karakiewicz P, Shariat SF, Graefen M, Huland H, Chun FK, Pompe RS: The impact of time to catheter removal on short-, intermediate- and long-term urinary continence after radical prostatectomy. World J Uro/2018, 36(8):1247-1253. https://doi.org/10.1007/s00345-018-2274-y

3. Hatiboglu G, Teber D, Tichy D, Pahernik S, Hadaschik B, Nyarangi-Dix J, Hohenfellner M: Predictive factors for immediate continence after radical prostatectomy. World J Urol 2016, 34(1):113-120. https://doi.org/10.1007/s00345-015-1594-4

4. Palisaar JR, Roghmann F, Brock M, Löppenberg B, Noldus J, von Bodman C: Predictors of short-term recovery of urinary continence after radical prostatectomy. World J Urol 2015, 33(6):771-779. https://doi.org/10.1007/s00345-014-1340-3

5. Matsushima M, Miyajima A, Hattori S, Takeda T, Mizuno R, Kikuchi E, Oya M: Comparison of continence outcomes of early catheter removal on postoperative day $\mathbf{2}$ and $\mathbf{4}$ after laparoscopic radical prostatectomy: a randomized controlled trial. $B M C$ Urol 2015, 15:77. https://doi.org/10.1186/s12894-015-0065-y

6. Sedor J, Mulholland SG: Hospital-acquired urinary tract infections associated with the indwelling catheter. The Urologic clinics of North America 1999, 26(4):821-828. https://doi.org/10.1016/s00940143(05)70222-6

7. Moore KN, Estey A: The early post-operative concerns of men after radical prostatectomy. Journal of advanced nursing 1999, 29(5):1121-1129. https://doi.org/10.1046/j.1365-2648.1999.00995.x

8. Lepor $\mathrm{H}$, Nieder AM, Fraiman MC: Early removal of urinary catheter after radical retropubic prostatectomy is both feasible and desirable. Urology 2001, 58(3):425-429. https://doi.org/10.1016/s0090-4295(01)01218-3

9. Patel R, Lepor H: Removal of urinary catheter on postoperative day 3 or $\mathbf{4}$ after radical retropubic prostatectomy. Urology 2003, 61(1):156-160. https://doi.org/10.1016/s0090-4295(02)02105-2

10. Peyronnet B, Brucker BM: Management of Overactive Bladder Symptoms After Radical Prostatectomy. Curr Urol Rep 2018, 19(12):95. https://doi.org/10.1007/s11934-018-0847-3 
11. Patel VR, Abdul-Muhsin HM, Schatloff O, Coelho RF, Valero R, Ko YH, Sivaraman A, Palmer KJ, Chauhan S: Critical review of 'pentafecta' outcomes after robot-assisted laparoscopic prostatectomy in high-volume centres. BJU international 2011, 108(6 Pt 2):1007-1017. https://doi.org/10.1111/j.1464-410X.2011.10521.x

12. Ficarra V, Novara G, Rosen RC, Artibani W, Carroll PR, Costello A, Menon M, Montorsi F, Patel VR, Stolzenburg J-U et al: Systematic Review and Meta-analysis of Studies Reporting Urinary Continence Recovery After Robot-assisted Radical Prostatectomy. European Urology 2012, 62(3):405-417. https://doi.org/https://doi.org/10.1016/j.eururo.2012.05.045

13. Litwiller SE, Kim KB, Fone PD, deVere White RW, Stone AR: Post-Prostatectomy incontinence and the Artificial Urinary Sphincter: A Long-Term Study of Patient Satisfaction and Criteria for Success. The Journal of Urology 1996, 156(6):1975-1980. https://doi.org/https://doi.org/10.1016/S00225347(01)65408-9

14. Tiguert R, Rigaud J, Fradet Y: Safety and outcome of early catheter removal after radical retropubic prostatectomy. Urology 2004, 63(3):513-517. https://doi.org/10.1016/j.urology.2003.10.042

15. Cormio L, Di Fino G, Scavone C, Maroscia D, Mancini V, Ruocco N, Bellanti F, Selvaggio O, Sanguedolce F, Lucarelli G et al: Prognostic Factors for Anastomotic Urinary Leakage Following Retropubic Radical Prostatectomy and Correlation With Voiding Outcomes. Medicine 2016, 95(16):e3475. https://doi.org/10.1097/md.0000000000003475

16. Huang $X$, Wang $L$, Zheng $X$, Wang $X$ : Comparison of perioperative, functional, and oncologic outcomes between standard laparoscopic and robotic-assisted radical prostatectomy: a systemic review and meta-analysis. Surgical Endoscopy 2017, 31(3):1045-1060. https://doi.org/10.1007/s00464-016-5125-1

17. Porpiglia F, Bertolo R, Manfredi M, De Luca S, Checcucci E, Morra I, Passera R, Fiori C: Total Anatomical Reconstruction During Robot-assisted Radical Prostatectomy: Implications on Early Recovery of Urinary Continence. Eur Urol 2016, 69(3):485-495. https://doi.org/10.1016/j.eururo.2015.08.005

18. Haga N, Ogawa S, Yabe M, Akaihata H, Hata J, Sato Y, Ishibashi K, Hasegawa O, Kikuchi K, Shishido $\mathrm{F}$ et al: Association between postoperative pelvic anatomic features on magnetic resonance imaging and lower tract urinary symptoms after radical prostatectomy. Urology 2014, 84(3):642-649. https://doi.org/10.1016/j.urology.2014.04.044

19. Cakmak S, Canda AE, Ener K, Atmaca AF, Altinova S, Balbay MD: Does Type 2 Diabetes Mellitus Have an Impact on Postoperative Early, Mid-Term and Late-Term Urinary Continence After Robot-Assisted Radical Prostatectomy? Journal of endourology 2019, 33(3):201-206. https://doi.org/10.1089/end.2018.0822

20. Huang J, Wang Y, An Y, Liao Y, Qiu M: Impact of Diabetes Mellitus on Urinary Continence Recovery after Radical Prostatectomy: a Systematic Review and Meta-Analysis. Urology journal 2020 , 18(2):136-143. https://doi.org/10.22037/uj.v16i7.5750 
Figures

80

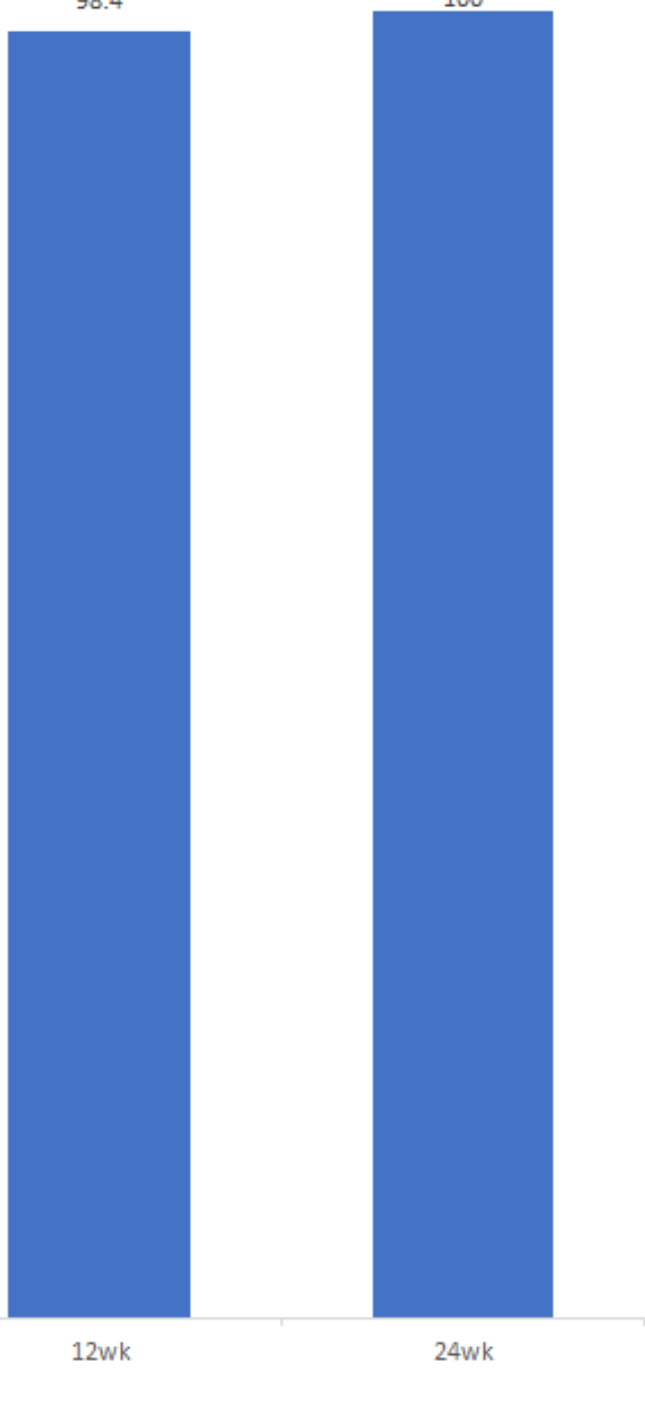

Figure 1

Continence rates at different times after catheter removal. 


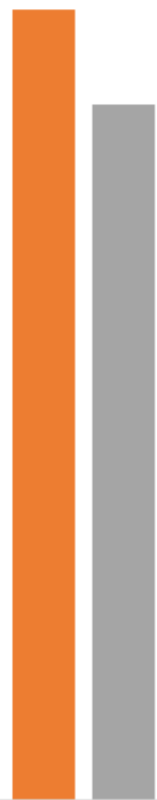

$1 w k$
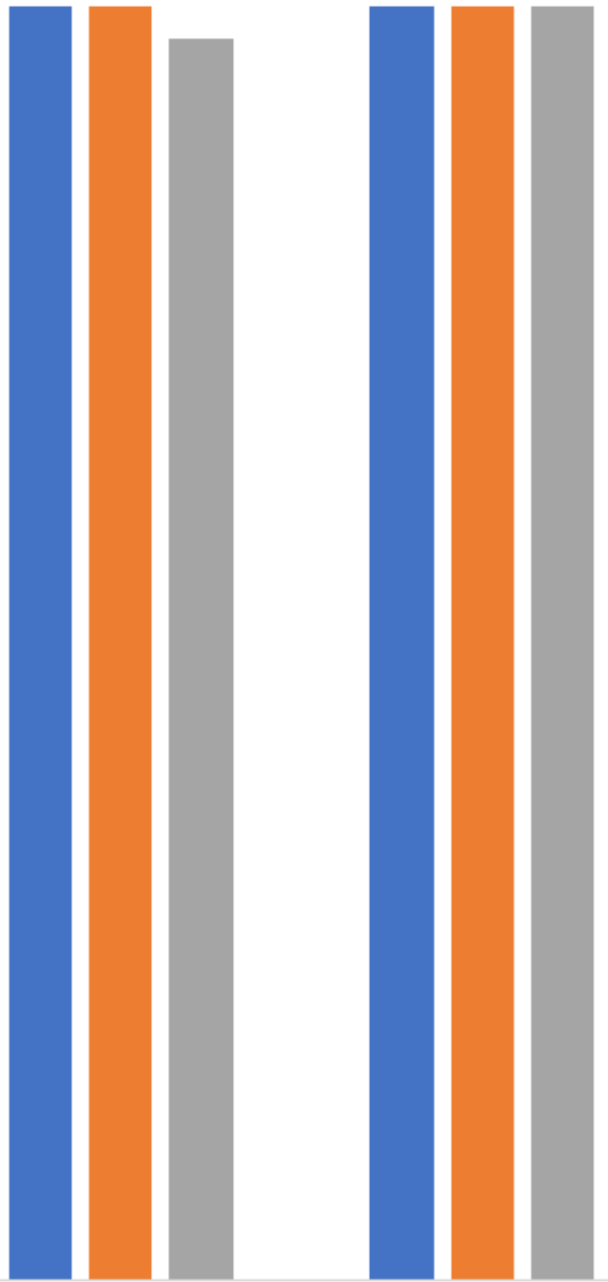

$4 \mathrm{wk}$

$12 w k$

$24 w k$

a days 10 days $\square \geq 14$ days

Figure 2

Continence rates at different times stratified by catheterization time
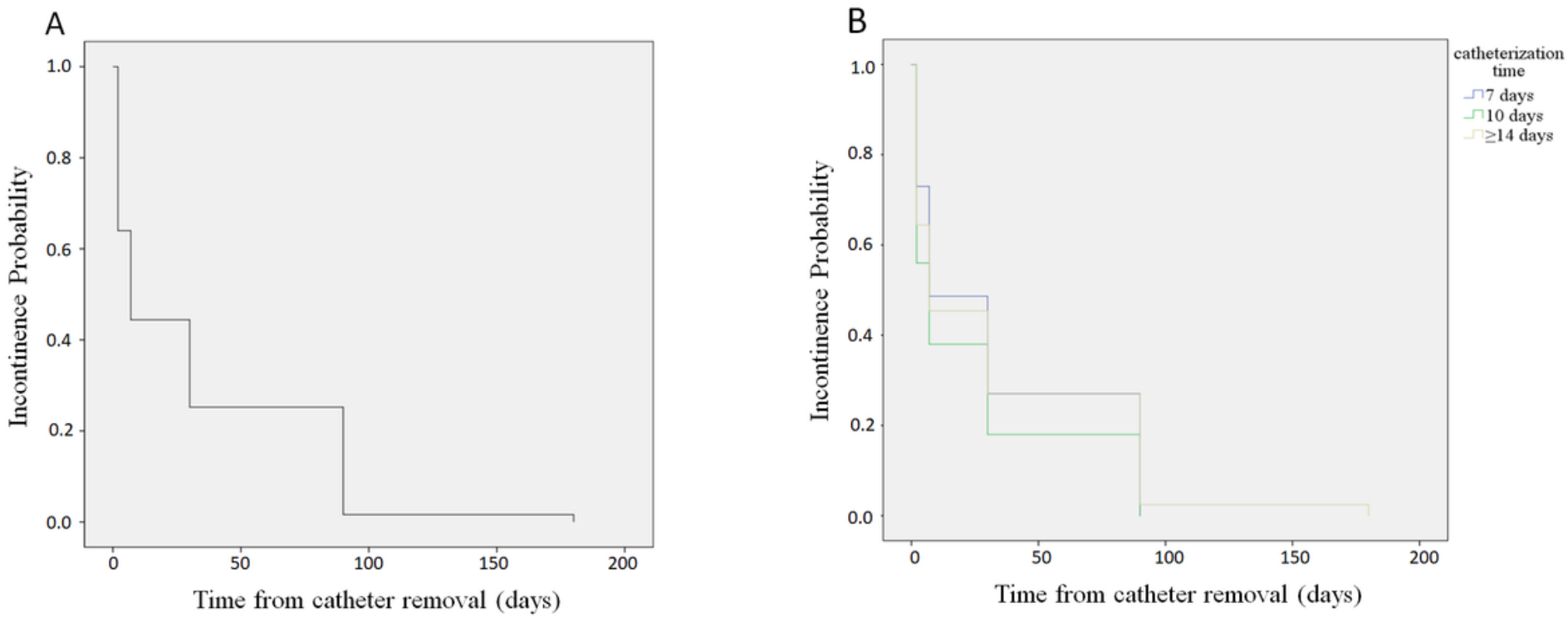
Figure 3

a. Kaplan-Meier curves of incontinence probability in all patients. b. Kaplan-Meier curves of incontinence stratified by different catheterization times.

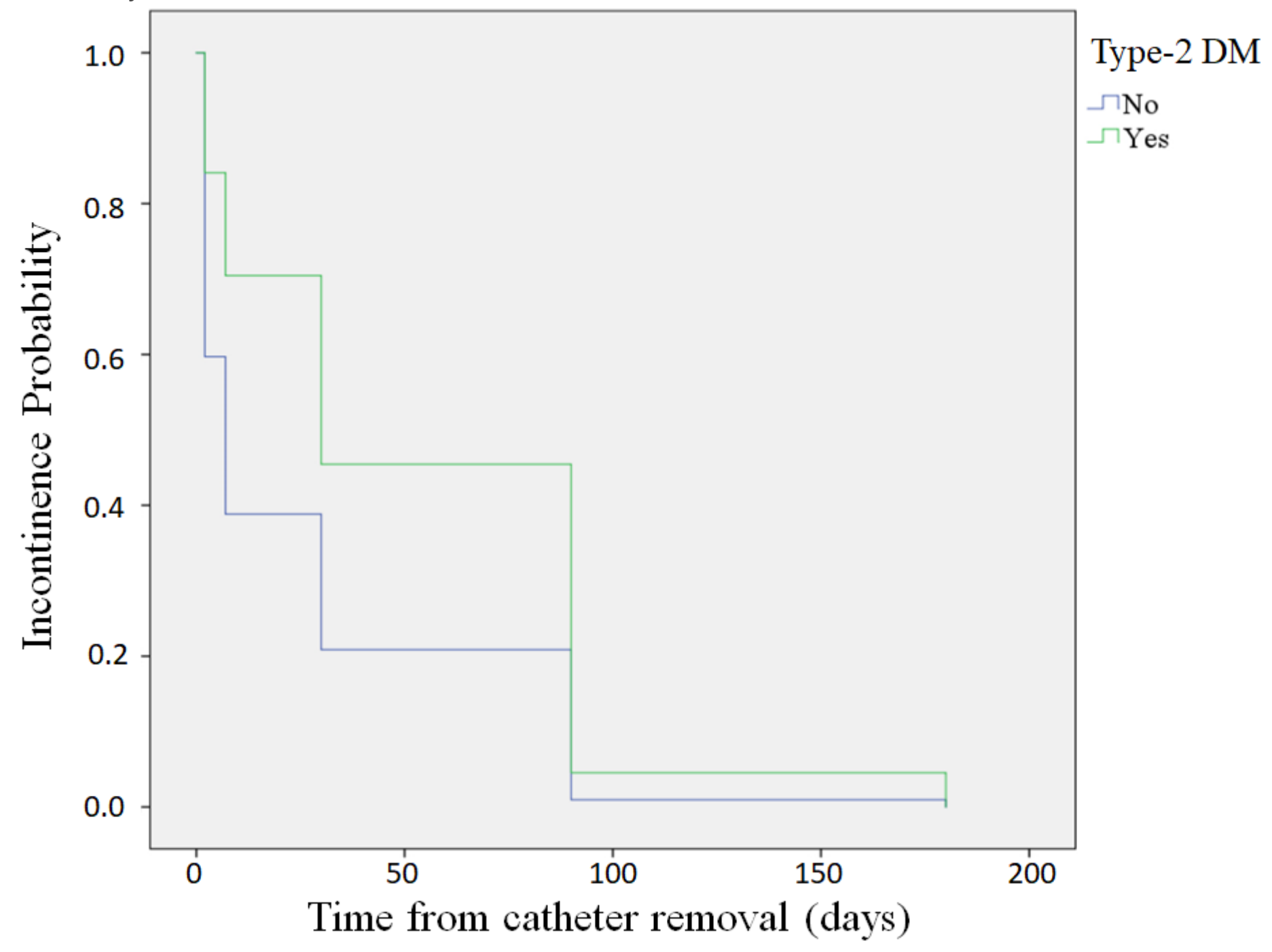

Figure 4

Impact of diabetes on incontinence probability. DM = Diabetes Mellitus

\section{Supplementary Files}

This is a list of supplementary files associated with this preprint. Click to download.

- Additionalfile1.xlsx 